\title{
Atividade investigativa remota de biologia do desenvolvimento: tipos de ovos na evolução dos animais
}

Flavia Sant'Anna Rios ${ }^{1}$

\section{RESUMO}

Uma atividade investigativa presencial abordando o tema Tipos de Ovos é realizada regularmente com os estudantes do Curso de Ciências Biológicas da Universidade Federal do Paraná (UFPR) durante a disciplina de Biologia do Desenvolvimento. No ano de 2020, em decorrência da pandemia pela COVID-19, tal disciplina foi ofertada na modalidade de Ensino Remoto Emergencial. A fim de adaptar essa atividade, foram empregados recursos de forma assíncrona utilizando AVA - Plataforma Moodle: videoaula gravada, montagem de árvore filogenética com os tipos de ovos e elaboração de hipótese. No encontro síncrono, foi realizada discussão do tema com auxílio do aplicativo Kahoot. Após o encontro, os discentes elaboraram suas conclusões. A adaptação para o Ensino Remoto mostrou-se viável e auspiciosa, favorecendo o pensamento científico.

Palavras-chave: Embriologia. Ensino Remoto Emergencial. Filogenia. Kahoot.

\footnotetext{
${ }^{1}$ flaviasrios@ufpr.br - Universidade Federal do Paraná - Departamento de Biologia Celular
} 


\title{
Remote investigative activity of development biology: types of eggs in the evolution of animals
}

\begin{abstract}
Usually, a face-to-face activity is carried out addressing the theme "Types of Eggs" in an investigative way for the Biological Sciences Course at Universidade Federal do Paraná during Developmental Biology classes. In 2020, due to the Covid-19 pandemic, the discipline was offered in the Emergency Remote Education modality. In order to adapt this activity, resources were used asynchronously using Moodle: recorded video class, assembly of a phylogenetic tree with the types of eggs and hypothesis elaboration. At the synchronous meeting, the topic was discussed using Kahoot application. After the meeting, the students elaborated their conclusions. The adaptation to remote teaching proved to be viable and auspicious, favoring scientific thinking.
\end{abstract}

Keywords: Embryology. Emergency Remote Teaching. Phylogeny. Kahoot. 


\section{INTRODUÇÃO}

Em decorrência da pandemia pela COVID-19, doença causada pelo novo coronavírus (SARSCoV-2), a partir de março de 2020 , as atividades presenciais em creches, escolas, universidades, institutos federais e demais espaços formais e não formais de ensino, públicos ou privados, foram suspensas e o Ensino Remoto Emergencial (ERE) foi colocado como alternativa para continuidade das atividades educacionais no Brasil (BRASIL, 2020a; 2020b; 2020c; MORAES et al., 2020), sendo que a situação prolongou-se até o final daquele ano letivo em grande parte das instituições, estendendo-se para o ano de 2021 em muitas.

Nesse sentido, a partir de junho de 2020, foram instituídos e regulamentados, em caráter excepcional, períodos especiais para o desenvolvimento de atividades remotas de ensino nos cursos de Educação Superior da Universidade Federal do Paraná (UFPR) em razão das medidas de enfrentamento da pandemia no país (UFPR, 2020a; 2020b). De acordo com essas resoluções, ficou autorizada a oferta facultativa de disciplinas obrigatórias ou optativas, independente das matrículas previamente realizadas no primeiro semestre de 2020.

De acordo com Behar (2020), o Ensino Remoto Emergencial e a Educação a Distância (EaD) não podem ser compreendidos como sinônimos, pois o ERE caracteriza-se pelo distanciamento geográfico imposto abruptamente, obrigando a adaptação emergencial do Ensino Presencial, que precisou ser transposto para os meios digitais. Visto que o currículo da maior parte das instituições educacionais não foi criado para ser aplicado remotamente, foi preciso pensar em atividades pedagógicas mediadas pelo uso da internet, minimizando os impactos na aprendizagem (BEHAR, 2020). Considerando a falta de organização prévia para essa situação, Rabello (2020) destaca que o ERE constitui um desafio para os educadores, causando questionamentos sobre como adaptar os conteúdos, as dinâmicas de sala, as aulas expositivas e as avaliações sem prejudicar o processo de aprendizagem, bem como manter os estudantes interessados e engajados.

Nesse contexto, a disciplina Biologia do Desenvolvimento, que faz parte da grade de disciplinas obrigatórias para o segundo período do curso de Ciências Biológicas da UFPR, foi idealizada para o Ensino Presencial. Entretanto, desde sua primeira oferta em 2008, um ambiente virtual de aprendizagem (AVA) disponibilizado pela plataforma Moodle, é utilizado como apoio às atividades presenciais, representando um repositório de materiais de consulta e meio de realização de algumas avaliações auxiliares. Assim, a docente responsável pela disciplina já tinha alguma familiaridade com essas ferramentas educacionais para o Ensino Remoto ou EaD.

Dentre os conteúdos abordados na disciplina, o estudo da classificação dos animais quanto à quantidade e distribuição de vitelo é um tema que integra a Embriologia à Zoologia. $O$ estudo da embriogênese de forma comparativa representa um vasto caminho para a compreensão das relações filogenéticas para os mais diversos grupos animais (ASSUNÇÃO; MIGLINO, 2020). Contudo, tradicionalmente, tanto no Ensino Médio quanto no Superior, o assunto é abordado por meio de aulas expositivas e exige memorização da classificação zoológica de acordo com os tipos de ovos e de clivagem e, com frequência, o estudante prende-se a decorar informações, não sendo estimulado a fazer descobertas. A observação empírica que muitos professores de biologia 
fazem de suas turmas permite constatar que essa abordagem conservadora dificilmente leva o aluno à compreensão dos processos adaptativos relacionados à conversão de energia do vitelo, tampouco ao entendimento do aspecto evolutivo envolvido, tendendo, assim, a não fixar os conteúdos. Essa dificuldade possivelmente advém da fragmentação dos saberes científicos que, segundo Gerhard e Rocha-Filho (2012), é fruto da visão mecanicista de mundo que "termina por prejudicar a formação integral e o conhecimento científico dos alunos, pois tolhe deles os resultados realmente úteis do conhecimento, como a capacidade de pensar globalmente certo problema" (GERHARD; ROCHA-FILHO, 2012, p. 127).

Apesar disso, na modalidade presencial, esse conteúdo vinha sendo ministrado para o referido curso de 2013 a 2019 com auxílio da estratégia descrita por Zanin e Rios (2014), que consiste da utilização de peças elaboradas com isopor e massa de biscuit representando tipos de ovos - alécitos, oligolécitos, mesolécitos, centrolécitos e telolécitos -, que devem ser dispostas sobre um painel sobre o qual foi impressa uma árvore filogenética com os principais filos de animais. Organizados em cima do painel, os ovos do mesmo tipo devem ser agrupados com auxílio de barbantes coloridos. A disposição das peças, formando conjuntos, favorece a percepção de uma relação entre os tipos de ovos e o processo evolutivo. Ao longo desse período, a atividade foi sendo adaptada, incorporando-se a utilização da ferramenta digital Kahoot, aplicada em sala de aula, como auxiliar no processo de reflexão e discussão sobre a relação entre a quantidade e distribuição de vitelo nos ovos de animais dos diferentes filos. O Kahoot é um aplicativo projetado para sondagens e avaliação da aprendizagem, que introduz na sala de aula a aprendizagem baseada na gamificação (BOTTENTUIT JUNIOR, 2017). A gamificação consiste na utilização de certas estratégias dos games, ou jogos, fora do contexto destes, sendo capaz de motivar os indivíduos à ação, auxiliar na solução de problemas e promover aprendizagens (KAPP, 2012 apud FARDO, 2013). Esse fenômeno emergente deriva diretamente da popularização e popularidade dos games (FARDO, 2013) e tem sido apontado como uma tendência nas metodologias didáticas, capaz de engajar e motivar os estudantes à medida que são revistos os conteúdos trabalhados (DELLOS, 2015). Utilizado como recurso didático, o Kahoot proporciona maior agilidade nas avaliações, promovendo uma competição saudável, além de permitir um feedback imediato no progresso da aprendizagem (SANTOS; GUIMARÃES; CARVALHO, 2014).

Por meio da estratégia didática empregada presencialmente, é possível desenvolver a compreensão a respeito da lógica que permeia a complexidade morfológica e a diversidade estrutural em relação à disponibilidade de energia ao embrião, eliminando a necessidade de simples memorização. Contudo, em virtude da necessidade de ministrar a disciplina na forma de ERE em 2020, viu-se a necessidade de adequar a metodologia para que pudesse ser aplicada de forma remota, sem a possibilidade de utilizar os recursos concretos e tridimensionais - peças representando os tipos de ovos, painel e barbantes - e sem o acompanhamento presencial da docente para mediar as reflexões. Sendo assim, no presente trabalho, é descrito um relato de experiência dessa metodologia para o estudo da relação entre os tipos de ovos e a filogenia adaptada para o Ensino Remoto Emergencial, utilizando ambiente virtual de aprendizagem plataforma Moodle -, software para reunião remota da turma - Google Meet - e aplicativo de aprendizagem lúdica - Kahoot. 
A metodologia foi aplicada com uma turma de 48 estudantes do Curso de Ciências Biológicas da Universidade do Paraná, matriculados na disciplina Biologia do Desenvolvimento e ministrada na forma de Ensino Remoto Emergencial. Essa turma é mista, tendo discentes do curso diurno e noturno. Os conteúdos da disciplina foram divididos em 15 unidades didáticas e a presente atividade fez parte da Unidade 2: O Início do Desenvolvimento, dedicada ao estudo da fecundação, tipos de ovos e clivagem.

A atividade foi desenvolvida em quatro etapas, sendo as duas primeiras de forma assíncrona e pré-encontro - montagem da árvore filogenética e formulação de hipóteses -; a terceira durante o encontro síncrono - discussão das hipóteses -; e a quarta também assíncrona e pós-encontro - elaboração das conclusões e feedback. As quatro etapas foram realizadas ao longo de um período de sete dias, de 07 a 13 de novembro de 2020.

Utilizou-se o ambiente virtual de aprendizagem (AVA) Moodle para as ações assíncronas. A sala de aula virtual utilizada para o encontro síncrono foi efetivada pelo aplicativo Google Meet.

\subsection{Etapa 1: embasamento teórico}

No dia 7 de novembro, foi disponibilizada aos estudantes, por meio do AVA, uma videoaula gravada pela docente da disciplina. Na aula, com pouco mais de sete minutos, foi explicado quais são os tipos de ovos de acordo com a quantidade e distribuição de vitelo e elucidado com exemplos de animais que apresentam cada tipo de ovo. No final, sugeriu-se uma bibliografia de consulta e foi explicado como deveria proceder o estudo dirigido - etapas 2 e 3.

A videoaula foi postada em uma página do AVA juntamente com outra aula sobre vitelogênese em ovos megalécitos. Essa página teve 275 visualizações de 44 usuários durante o período da atividade.

\subsection{Etapa 2: organização da árvore filogenética e formulação de hipóteses}

A primeira parte do estudo dirigido consistiu na realização de um questionário no AVA, contendo duas questões. A primeira questão era do tipo "Arraste e solte na imagem", que permitia que rótulos de texto fossem arrastados e soltos em regiões alvo em uma imagem de fundo. A imagem de fundo utilizada era o desenho de uma árvore filogenética simplificada que continha fotos com exemplos de animais dos principais filos Figura 1). Os estudantes deviam arrastar para o lado da imagem de cada animal o nome do respectivo tipo de ovo - alécito, oligolécito, mesolécito, telolécito e centrolécito. 
Figura 1: Questão 1 do questionário pré-encontro. Questão do tipo “Arraste e solte na imagem”, em que os estudantes deviam associar o tipo de ovo - alécito, oligolécito, mesolécito, telolécito e centrolécito - com os grupos de animais distribuídos na árvore filogenética.

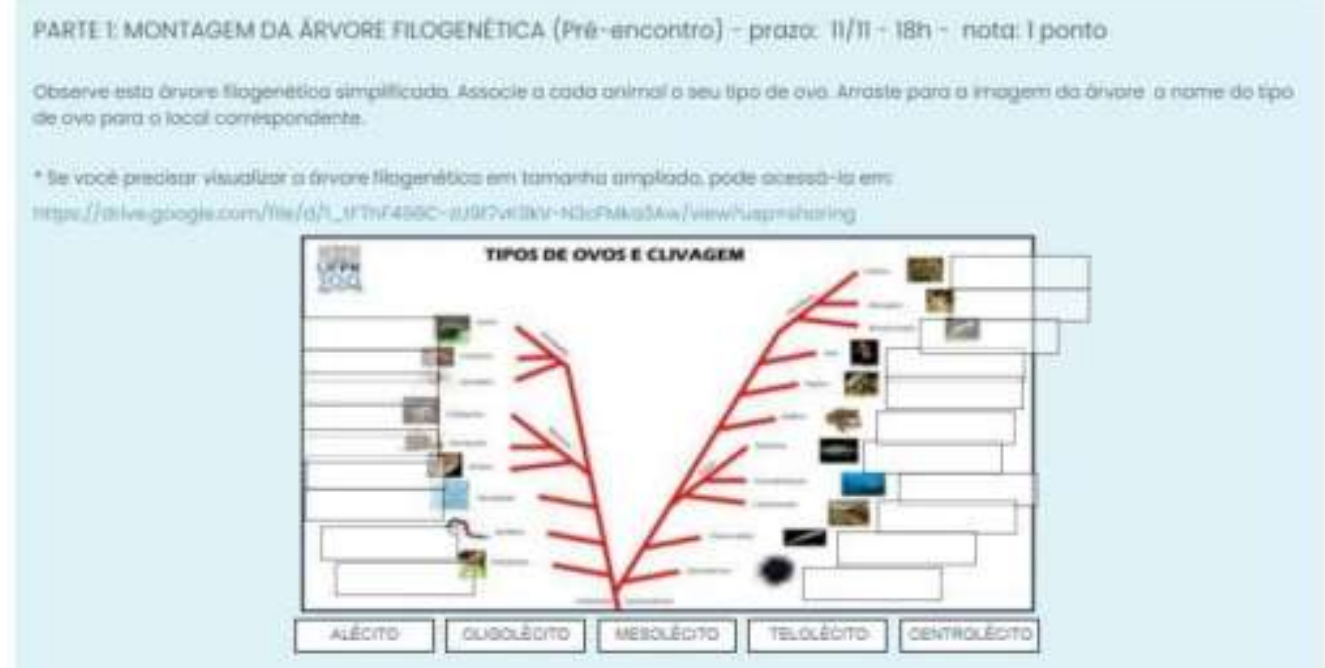

Fonte: elaborado pela autora, com base na pesquisa realizada.

A segunda era uma questão dissertativa com o seguinte enunciado: "Após assistir à videoaula sobre Tipos de Ovos e montar a árvore filogenética com os tipos de ovos na Parte 1 dessa atividade, observe atentamente o resultado da distribuição dos tipos de ovos nos diferentes grupos animais. Mentalmente, agrupe os animais com mesmos tipos de ovos. Analise se existe uma lógica, um padrão e/ou uma tendência nessa distribuição de tipos de ovos quanto à quantidade e distribuição de vitelo nos diferentes grupos de animais. Elabore uma hipótese para explicar o que você observa e descreva-a no espaço abaixo, explicando sua linha de raciocínio para chegar a essa hipótese. É possível que você chegue a mais de uma hipótese, mas escolha apenas uma, aquela que achar mais plausível" (Figura 2).

Figura 2: Questão 2 do questionário pré-encontro. Questão aberta, na qual os estudantes deveriam elaborar uma hipótese para a relação entre a quantidade e distribuição de vitelo e a organização filogenética dos animais, descrevendo a sua linha de raciocínio.

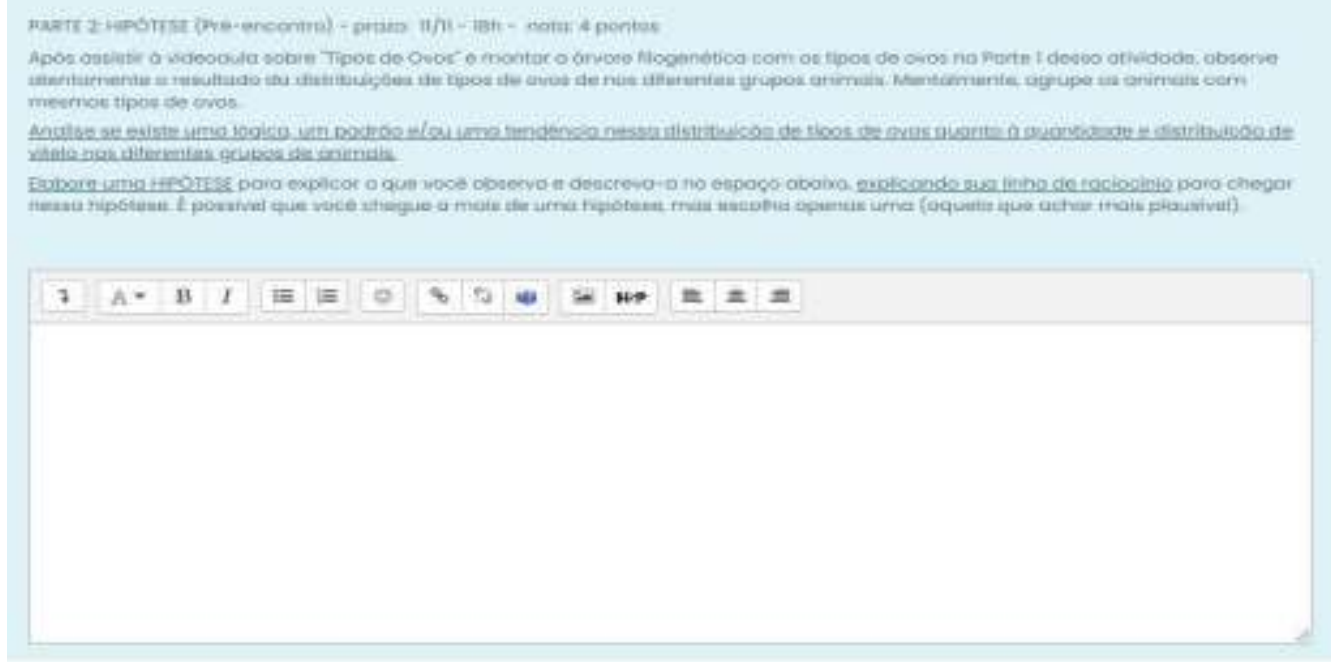

Fonte: elaborado pela autora, com base na pesquisa realizada 
Os estudantes tiveram 5 dias para cumprir essa etapa e deveriam responder com, no máximo 150 palavras. Dos 48 estudantes, 42 responderam o questionário. Visando a pontuação, foram consideradas a escolha correta dos tipos de ovos - questão $1 ; 1$ ponto - e as hipóteses coerentes e bem descritas, ainda que não estivessem corretas - questão 2; 4 pontos. 0 desempenho dos 42 alunos participantes foi de, em média, $84,4 \%$ de aproveitamento.

\subsection{Etapa 3: discussão das hipóteses}

No dia 11 de novembro, das $19 \mathrm{~h}$ às $21 \mathrm{~h}$, foi realizado o encontro síncrono. Previamente, foi informado aos estudantes que seria utilizado o aplicativo Kahoot, uma plataforma gratuita de aprendizado baseada em jogos, disponível no próprio site, bem como nas lojas de aplicativos dos sistemas operacionais de smartphones - Android e iOS. Tal aplicativo já havia sido utilizado por essa turma na semana anterior para outra atividade, com a possiblidade de ser operado no smartphone ou computador, sem a necessidade de fazer download.

Por meio desse aplicativo, ao compartilhar a tela através do Google Meet, a docente projetava perguntas de um quiz e, em seus dispositivos - smartphones ou computadores -, os estudantes escol hiam as respostas que consideravam corretas. O número de respostas para cada alternativa era exposto na tela ao final do tempo destinado para cada questão - 20 a 30 segundos. Foram realizados dois quizzes. Quarenta estudantes participaram do encontro síncrono; apenas 31 utilizaram o Kahoot durante o primeiro quiz, e, no segundo, foram 32.

O primeiro quiz era composto de nove questões sobre os tipos de ovos quanto à quantidade e distribuição de vitelo e visava verificar se os estudantes compreenderam quais eram os critérios para classificação e, consequentemente, a nomenclatura empregada. Entre uma questão e outra, o aplicativo mostra quais são as alternativas corretas e a pontuação dos alunos. Nesse momento, a docente fazia pausas para explicar por que cada alternativa estava certa ou errada, abrindo espaço para discussões e questionamentos; entretanto, não houve manifestações orais, embora todos os participantes tenham respondido às questões por intermédio do aplicativo. A última questão foi a seguinte: "Existe relação entre a quantidade e distribuição de vitelo e a evolução dos animais?". De forma proposital, a resposta correta era "Talvez", pois, na sequência, seriam expostas as hipóteses levantadas pelos estudantes.

Antes da aplicação do segundo quiz, a docente projetou a imagem da árvore filogenética com os respectivos tipos de ovos agrupados em tipos semelhantes (Figura 3), que era similar àquela montada pelos estudantes por meio do questionário no Moodle antes do encontro. Destacou-se, nesse momento, que há um evidente agrupamento dos tipos de ovos relacionado à classificação zoológica.

O segundo quiz, aplicado em seguida, era composto pelas principais hipóteses levantadas pelos estudantes na etapa pré-encontro - questão discursiva do questionário. Para elaborar as questões do quiz, a docente analisou as hipóteses enviadas pelos alunos até as $16 \mathrm{~h}$ do mesmo dia do encontro. Estas foram apresentadas de forma resumida, sendo que a maior parte das questões foi elaborada na forma de verdadeiro e falso. 
Figura 3: Árvore filogenética mostrando os agrupamentos dos tipos de ovos: Isolécitos, ou Oligolécitos; Heterolécitos, ou Mesolécitos; Centrolécitos e Telolécitos. Mamíferos Eutérios e Marsupiais foram considerados Alécitos.

\section{Alécitos}

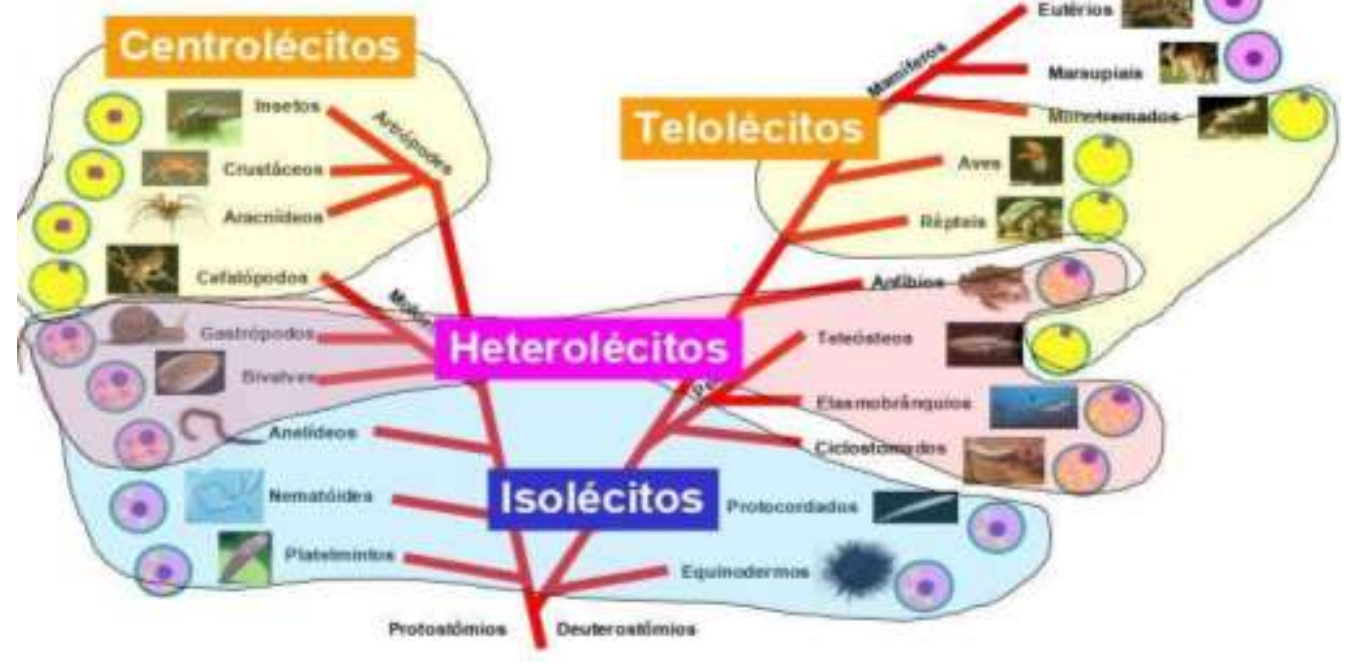

Fonte: elaborado pela autora com base na pesquisa realizada.

Inicialmente, questionou-se se "a quantidade de vitelo é diretamente proporcional à necessidade de nutrição", e se "a quantidade de vitelo parece ter uma relação com a evolução", sendo essas duas afirmações consideradas verdadeiras. Da mesma forma que no primeiro quiz, fizeram-se pausas entre uma questão e outra para explicações e eventuais discussões - Figura 4. Considerando-se, portanto, que a quantidade de vitelo segue um padrão que acompanha a filogênese, a seguir, questionou-se qual seria a explicação para tal relação.

Figura 4: Tela durante o encontro síncrono no Google Meet, exibindo o andamento de um quiz com auxílio do aplicativo Kahoot.

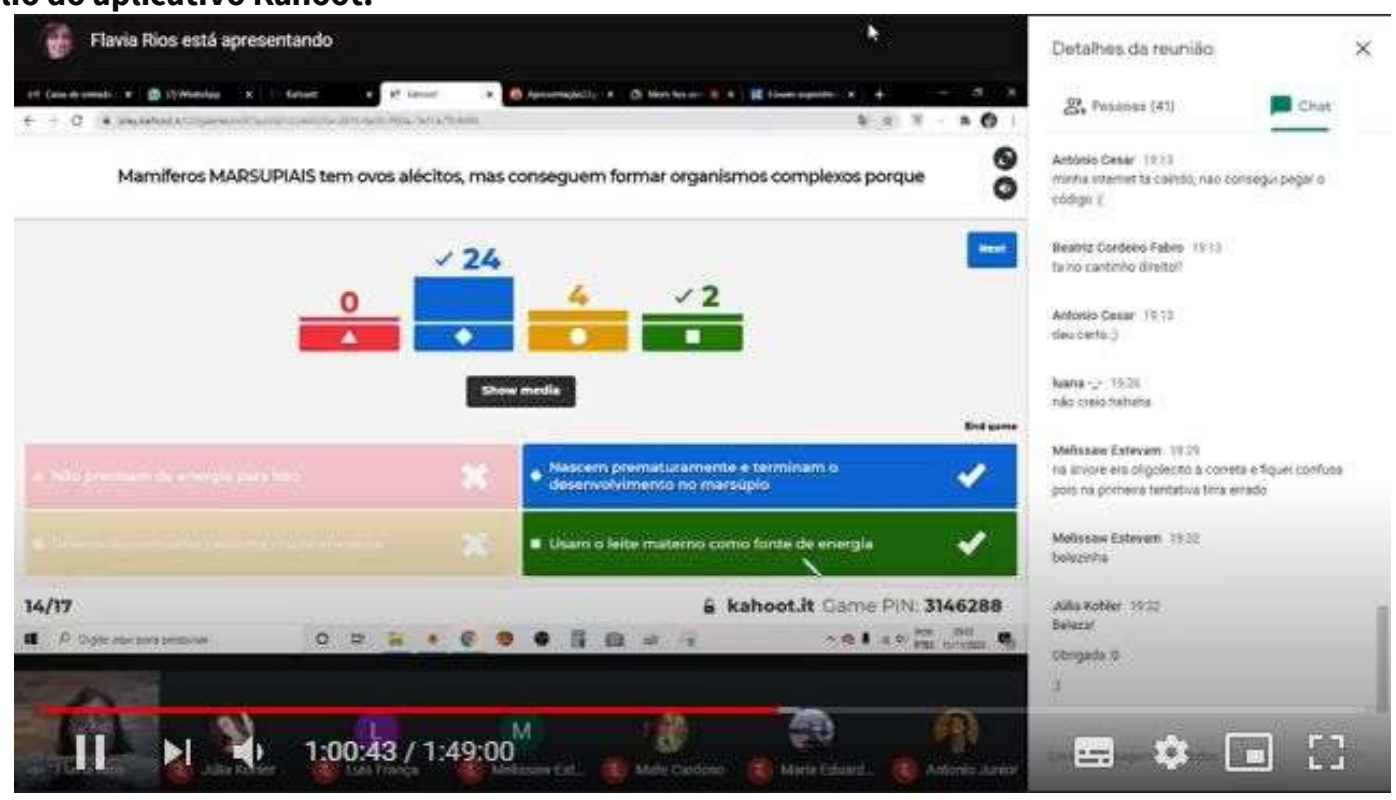

Fonte: Elaborado pela autora com base na pesquisa realizada. 
A maioria das hipóteses apresentadas pelos estudantes na etapa 1 baseava-se no fato do desenvolvimento ser interno ou externo, sendo atribuída maior quantidade de vitelo àqueles com desenvolvimento externo (Figura 5); Interno/Externo. Muitos mencionaram a presença da placenta e a participação direta da mãe no desenvolvimento embrionário nos mamíferos, ou seja, o desenvolvimento interno, como um fator que compensaria a menor quantidade de vitelo em seus ovos. Nota-se que não foi levada em consideração por essa grande proporção de estudantes que uma ampla gama de invertebrados com ovos oligolécitos também apresentam desenvolvimento externo.

Vários estudantes relacionaram a distribuição dos tipos de ovos com o processo evolutivo e com os tipos de clivagem, embora essas relações não constituam propriamente hipóteses que pudessem explicar o que foi solicitado, sendo que apenas um estudante admitiu não saber explicar, apesar de ter feito uma tentativa de argumentação - Figura 5. Cerca de um terço da turma relacionou a maior disponibilidade de vitelo com a complexidade morfológica atingida ao final do desenvolvimento embrionário, que era a relação esperada. Um menor número de estudantes tentou relacionar a situação observada no desenho da árvore filogenética com condições ambientais, tais como temperatura e presença de água - ambiente terrestre ou aquático -; hostilidade do ambiente; tempo ou velocidade de desenvolvimento; modo de desenvolvimento - ovulíparos, ovíparos ou vivíparos -; tipo de fecundação - interna ou externa ; cuidados parentais após o nascimento ou eclosão; metabolismo - alto ou baixo -; e necessidades nutricionais particulares de certos grupos animais, sendo citada ainda a presença de marsúpio e de estágio larva - desenvolvimento indireto -, conforme Figura 5 abaixo.

Figura 5: Nuvem de palavras representando as principais hipóteses levantadas pelos estudantes na Etapa 1 da atividade.

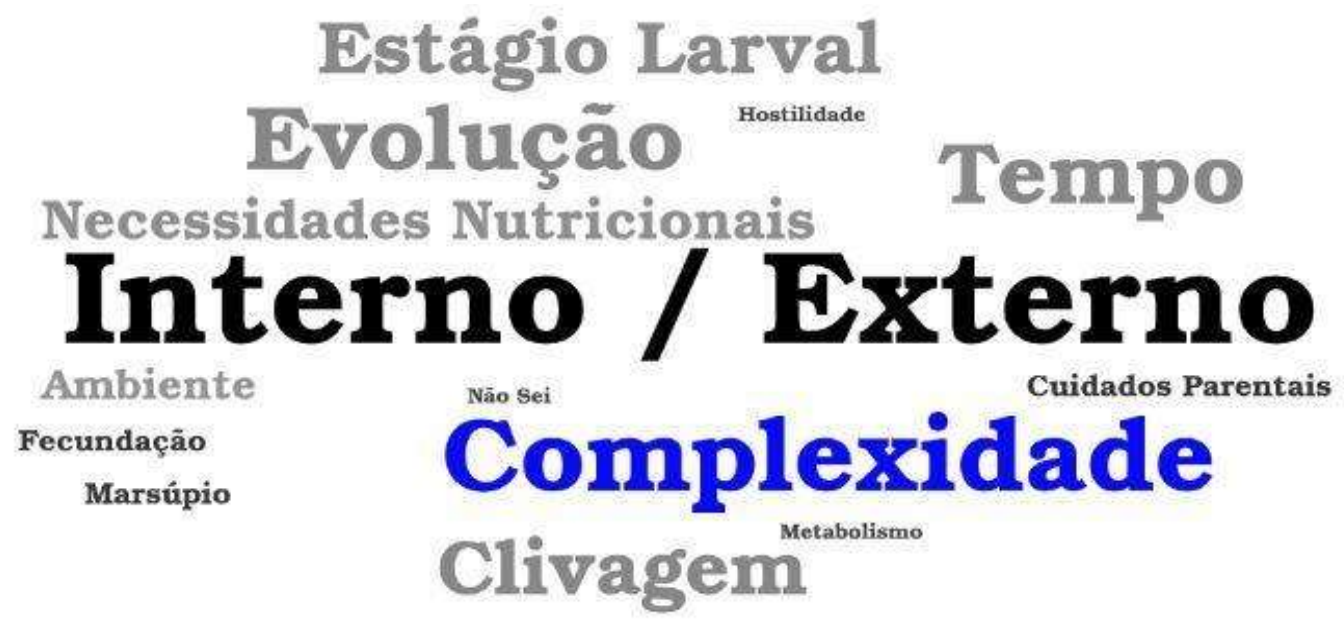

Fonte: elaborado pela autora, com base na pesquisa realizada.

OBS: O tamanho da fonte é diretamente proporcional ao número de vezes que a ideia foi apresentada como hipótese pelos estudantes. A complexidade morfológica era a relação esperada, ou seja, quanto maior a disponibilidade de energia na forma de vitelo ou a partir dos nutrientes provenientes da placenta ou do leite no marsúpio, maior a complexidade. 
Durante a etapa 2 - quiz 2 -, discutiu-se as hipóteses uma a uma, mostrando que todas essas situações poderiam parecer verdadeiras à primeira vista, mas que todas elas apresentavam exceções. Com relação à variável "tempo de desenvolvimento", discutiu-se que poderia ser considerada correta se fosse levado em conta um tempo relativo, mas não absoluto, uma vez que está na dependência da taxa metabólica, que por sua vez varia em função de variáveis ambientais, tais como temperatura e disponibilidade de oxigênio.

Então, apresentou-se a afirmação "quanto mais vitelo, maior é a complexidade do organismo" e as alternativas de resposta eram: "falso"; "exatamente isso"; "parece que sim, mas tem exceções"; "justamente o contrário", tendo sido considerada certa "parece que sim, mas tem exceções". Nas questões seguintes e respectivas discussões, esclareceu-se que, na realidade, quanto maior a quantidade de energia disponível, maior a complexidade morfológica dos organismos; mas, que essa energia, isto é, nutrientes não necessariamente deveria ser proveniente do vitelo. Nesse ponto, foi citado o caso dos mamíferos Euthera, ou placentários, que desenvolveram uma novidade evolutiva, a placenta, por meio da qual o embrião obtém os nutrientes necessários sem a exigência de uma reserva energética - vitelo - no gameta feminino. Do mesmo modo, o caso dos mamíferos marsupiais, que na escassez de vitelo e ausência de uma placenta bem desenvolvida, nascem muito prematuramente e alojam-se no marsúpio, no qual obtém energia a partir do leite materno, permitindo o término de seu desenvolvimento. Discutiuse, ainda, o caso dos peixes que têm mais vitelo que os anfíbios embora sejam evolutivamente mais antigos, e apresentou-se uma imagem de larva de peixe, evidenciando que esses animais eclodem com um excesso de vitelo, que é utilizado no período larval - pós-embrionário -, antes que a larva livre natante seja capaz de se alimentar exogenamente. Destinou-se tempo para resolução de dúvidas e discussões durante e após o término do quiz, havendo, entretanto, poucas manifestações, em especial através do chat. Os estudantes que participaram da atividade pelo Kahoot, porém, mostraram-se envolvidos, respondendo de forma rápida e coerente.

\subsection{Etapa 4: Elaboração de conclusões e feedback}

Na última etapa dessa atividade, os estudantes deveriam elaborar um pequeno texto com no máximo 150 palavras, contendo as suas conclusões acerca da problemática levantada e discutida, e postar como tarefa no AVA até dois dias após o encontro. Nessa breve redação, deveriam, mais uma vez, apontar se existia uma lógica, padrão ou tendência na ocorrência de diferentes tipos de ovos de acordo com a quantidade e distribuição de vitelo nos diferentes filos de metazoários. Deveriam, ainda, comentar se sua hipótese inicial tinha sido ou não confirmada. Dos 48 estudantes matriculados, um total de 39 enviou suas respostas nessa etapa. Analisando os textos redigidos, constatou-se que a maioria dos estudantes compreendeu qual era a relação entre a quantidade de vitelo e a organização filogenética dos animais, sendo que $44 \%$ deles tiraram nota máxima - nota 5 -, e $26 \%$ tiveram um aproveitamento de $80 \%$ - nota entre 4 e 4,8. Daqueles que responderam, cerca de $10 \%$ não compreenderam a relação e os demais compreenderam parcialmente - notas menores que 3,9. 
Após a correção, a docente enviou um feedback para os estudantes no Fórum de Notícias Avisos - do AVA, a fim de esclarecer para aqueles que não haviam compreendido a relação ou que manifestaram dúvidas em suas conclusões. $O$ texto tinha o seguinte conteúdo:

Vocês elaboraram hipóteses coerentes e, durante o encontro, pudemos discutir a grande maioria delas, vendo se havia lógica e se explicavam o padrão observado. E quase todos vocês puderam entender por que algumas hipóteses foram descartadas e outras aceitas total ou parcialmente. Nossa conclusão foi que a disponibilidade de maior quantidade de energia, na forma de nutrientes - que pode ser proveniente do vitelo ou então diretamente da mãe por meio de trocas através da placenta ou do leite, no caso dos marsupiais -, permite o desenvolvimento de organismos com maior complexidade morfofisiológica. Alguns ficaram em dúvida sobre o que seria essa 'complexidade'. Podemos dizer que ela envolve um maior número de tecidos, tipos celulares, organização mais complexa de órgão e sistemas, controle fisiológico e imunológico que envolvem maior nível de detalhamento, etc. Percebam que, deste ponto de vista, os mamíferos não são exceção, e sim, incluem-se no padrão observado pois falamos em energia e não em vitelo necessariamente. Mas, obviamente, diminui a independência do embrião, que passa a depender da mãe durante todo o desenvolvimento e é claro que existem outras vantagens. Vocês estudarão em ecologia sobre os estrategistas K e R. É claro que tudo isso deve ser observado sempre com muita cautela, pois a Biologia é uma ciência complexa, visto que a variabilidade é gigantesca. Mas, nossa principal missão como biólogos é encontrar padrões e tentar explicá-los. O grande objetivo dessa atividade era estimular a observação de dados e, a partir disso, elaborar e testar hipóteses, acostumando-se a analisar criticamente aquilo que se observa. Alertar para o cuidado que devemos ter ao generalizar conclusões de observações pontuais. Com isso, pretendia-se demonstrar, nesse caso específico, que não é necessário decorar que grupos de animais tem quais tipos de ovos - afinal isso pode ser facilmente encontrado na literatura -, mas sim estabelecer uma relação entre energia disponivel para a morfogênese e os fenótipos desenvolvidos. Pelas conclusões enviadas, acredito que atingimos os objetivos, pelo menos com a maioria dos estudantes. Verificou-se, porém, que para alguns poucos estudantes, o tema ainda não ficou bem claro. Ficamos à disposição para voltar a discutir o assunto, que certamente virá à tona no decorrer dos próximos tópicos abordados. Parabéns a todos pela dedicação e textos enviados.

\section{COMPARAÇÃO DA APLICAÇÃO PRESENCIAL E REMOTA DA ATIVIDADE}

Quando essa atividade é desenvolvida presencialmente, trabalha-se com cinco grupos de até seis estudantes em cada turma de aula prática e todas as etapas ocorrem em um período de duas horas. Uma breve explicação sobre os tipos de ovos é feita, utilizando o quadro negro e giz, à medida que se aplica o primeiro quiz do Kahoot com auxílio de projetor multimídia. Depois, cada grupo de estudantes recebe um painel impresso, as peças de isopor e massa de biscuit, os barbantes e a cópia de um capítulo de livro sobre o assunto como fonte de consulta. A docente supervisiona e medeia a montagem da árvore filogenética por cada grupo, fazendo as correções necessárias. Em seguida, após alguns minutos de discussão em grupo, os estudantes elaboraram as hipóteses e as expõem para a turma. Na sequência, é aplicado o segundo quiz, que já havia sido previamente elaborado, não com as hipóteses da turma, mas com possíveis hipóteses, baseadas 
nas turmas anteriores. Ao final, as conclusões do grupo devem ser entregues na forma de relatório. Nas aplicações anteriores, os estudantes não receberam um feedback.

$\mathrm{Na}$ modalidade presencial, esse tipo de atividade vem a atender a necessidade de metodologias alternativas para o ensino de Embriologia e Biologia do Desenvolvimento, dada a dificuldade de acesso a lâminas histológicas em número e quantidade adequados pelas instituições de ensino e, conforme destacado por Assunção e Miglino (2020), pela impossibilidade legal e ética de se utilizar organismos vivos nas aulas. Na perspectiva da docente, a atividade vinha trazendo bons resultados, demonstrados mais pela motivação e interesse despertado, que pelo desempenho em avaliações formais.

Inicialmente, ao deparar-se com a necessidade de adaptar a metodologia para o Ensino Emergencial Remoto (ERE), tinha-se a preocupação que, devido ao distanciamento físico, a falta dos materiais concretos e a ausência de mediação e discussões durante a execução da atividade prejudicasse o entendimento e aproveitamento pelos estudantes. Esse receio baseou-se no entendimento de que o Ensino à Distância, conforme descrito por Santos (2009), seria baseado na metodologia tradicional de transmissão de conhecimentos, com pouco espaço para interatividade entre docentes e discentes, bem como entre colegas. De fato, conforme apontado por Maia e Silva (2020), o AVA costuma ser largamente utilizado para trocas e armazenamento de conteúdo em detrimento da utilização das ferramentas interativas da plataforma, que geralmente são subutilizadas. Essa constatação era condizente com a experiência prévia da docente que realizou a presente pesquisa.

Contudo, o resultado observado foi diferente do esperado, possivelmente devido às adaptações metodológicas e distintos espaços e momentos de aprendizagem, trazendo resultados bastante interessantes.

A distância física entre docentes e discentes é menos importante que a percepção psicológica de distanciamento que o estudante vivencia em atividades de ensino-aprendizagem tanto presenciais, quanto remotas (TORI, 2015). Segundo Tori (2015), as mídias interativas são bastante eficazes para eliminar distâncias em atividades remotas, podendo inclusive ser vantajosas quando comparadas a certas atividades presenciais. Nesse contexto, o autor cita as videoconferências, bem como o uso da gamificação, dentre outras metodologias.

$\mathrm{Na}$ presente pesquisa, comparando-se a modalidade remota à presencial, além da separação física, houve a disponibilização de uma aula gravada em substituição à explicação com quadro negro e giz, maior tempo para execução de todas as etapas - sete dias em vez de duas horas - e a realização da atividade de forma individual e não em grupo. É possível que, se a atividade fosse transposta para o ERE com menos adaptações, principalmente no que se refere ao tempo para realização das atividades, não teria sido viável ou, pelo menos, não teria resultados tão positivos.

A videoaula, com cerca de sete minutos de duração, deu a possibilidade para os estudantes visualizarem a explicação mais de uma vez. Em média, a pasta em que se localizava esta e mais outra aula, foi acessada mais de seis vezes por cada estudante. A disponibilização prévia da videoaula caracteriza a metodologia como sala de aula invertida, ou aprendizagem invertida, por meio da qual o estudante se prepara antes e no seu ritmo para poder participar em atividades significativas com colegas e docentes, transferindo para o digital uma parte do que costuma ser 
explicado em aula pelo professor (BACICH; MORAN, 2018). Nessa abordagem, respeita-se o tempo de cada indivíduo para assimilar o conteúdo e o estudante assume a responsabilidade pelo estudo teórico, ficando o tempo da aula presencial ou encontro síncrono destinado à prática, aos debates, à resolução de problemas e ao esclarecimento de dúvidas. Com isso, enfatiza-se o protagonismo dos estudantes, valorizando os seus conhecimentos prévios e aumentando seu envolvimento direto, participativo e reflexivo (MERIGUETE et al., 2019). Além disso, essa autonomia espacial e temporal, bem como a possibilidade de rever o conteúdo, favorece os estudantes que apresentam maior dificuldade de compreensão (BERGMANN; SAMS, 2018 apud MERIGUETE et al., 2019).

A elaboração individual da hipótese inicial e com um prazo de cinco dias - e não apenas alguns minutos como na aplicação presencial -, possibilitou que textos mais estruturados e diversificados fossem apresentados, pois, segundo Silva e Affeldt (2020), a escrita permite que o discurso seja "moldado" e elaborado. É bastante possível, inclusive, que tenha havido discussões e troca de informações entre os estudantes. Contudo, embora algumas ideias fossem semelhantes, os textos foram bastante diferentes entre si, demonstrando que, pelo menos a maioria, refletiu sobre a questão proposta e tentou explicar da melhor forma a sua linha de raciocínio. Os textos bem formulados demonstraram que os estudantes se dedicaram ao trabalho.

A interação entre professor e estudantes na elaboração de hipóteses, debates e conclusões se aproxima de uma investigação científica (AZEVEDO, 2004; SÁ; LIMA; AGUIAR JUNIOR, 2011). Hipóteses são consideradas explicações provisórias, que permitem uma interpretação da realidade, aproximando o estudante de atitudes científicas e contribuindo para a formação de um sujeito investigativo e interessado, que busca conhecer e compreender a realidade. Por mais simples que seja a experiência, atividades envolvendo resolução de problemas, tornam-se ricas ao revelar as contradições entre o pensamento do estudante, o limite de validade das hipóteses levantadas e o conhecimento científico (PARANÁ, 2008).

Bizzo (2009) destaca que não há necessidade de laboratórios equipados para que possamos criar um espaço de investigação. Uma atividade investigativa não precisa necessariamente ser um experimento, sendo que o mais importante é impulsionar os estudantes a resolver um problema proposto (AZEVÊDO; FIREMAN, 2017). De acordo com Bacich e Moran (2018), por meio de metodologias ativas, são criadas situações de aprendizagem com as quais os estudantes possam pensar, conceituar, construir conhecimentos sobre os conteúdos envolvidos nas atividades que realizam, bem como desenvolver a capacidade crítica, refletir sobre as práticas que realizam, fornecer e receber feedback.

Outrossim, metodologias ativas em contextos híbridos, que integram as tecnologias e mídias digitais trazem, ainda, mais mobilidade e diferentes experiências de aprendizagem, permitindo combinar e integrar de forma equilibrada a aprendizagem individual, pois cada estudante percorre e escolhe seu caminho, ao menos parcialmente, e avança no seu ritmo, buscando maior autonomia e personalização (BACICH; MORAN, 2018). Quando a prática é feita em grupo e presencialmente, apenas um estudante escreve aquilo que o grupo considera consenso; porém, não necessariamente reflete a opinião de todos. Além disso, o prazo curto não dá tempo para uma reflexão mais cuidadosa e eventual pesquisa. Assim, acredita-se que, do 
modo como foi aplicada a metodologia no ERE, foi possível que os estudantes refletissem mais e expressassem suas opiniões individuais, resultando em um amplo espectro de hipóteses.

No presente trabalho, os quizzes executados com auxílio do aplicativo Kahoot foram semelhantes àqueles usados presencialmente, no entanto pôde ser adaptado para que as hipóteses levantadas pela própria turma fossem inseridas e, assim, discutidas durante o encontro síncrono. Dessa forma, embora não tenham sido reveladas as autorias das hipóteses, cada estudante pôde reconhecer sua própria hipótese dentre aquelas expostas e avaliar se ela era válida. A percepção de que sua ideia inicial foi refutada com argumentos plausíveis dá ao estudante a possibilidade de ressignificá-la, pois, de acordo com Silva (2008), o erro construtivo surge durante o processo de redescoberta e reinvenção do conhecimento, podendo ser abandonado enquanto o indivíduo alcança um nível de elaboração mental superior.

Por outro lado, quando a atividade descrita é realizada em sala de aula presencial, costuma haver mais interação entre a docente e a turma, ainda que nem todos os estudantes costumem se manifestar. Na aplicação remota, $80 \%$ dos estudantes presentes utilizaram o aplicativo e interagiram, respondendo à maioria das questões. Porém, durante as pausas para discussão, houve pouquíssimas manifestações orais ou via chat. Esse foi o segundo encontro dessa turma na disciplina e observou-se que, a partir do terceiro encontro, a interação dos estudantes começou a aumentar gradativamente à medida que aumentava o vínculo entre estudantes e docentes e entre os próprios estudantes, visto que se trata de uma turma mista - estudantes do curso diurno, noturno e de diferentes períodos. A ausência do diálogo entre docentes e discentes pode resultar em desmotivação e consequente desistência dos estudantes nos cursos a distância (CRUZ, 2011 apud SILVA; PRADO; PASQUALINI, 2019). Entretanto, Silva e Affeldt (2020, p. 59) comentam que "quando enunciamos presencialmente, o silêncio não necessariamente significa o insucesso da comunicação" e isso pode ser comprovado tanto pela participação no Kahoot quanto pelos bons textos produzidos na etapa 4, trazendo as conclusões dos estudantes.

As produções de texto com as conclusões, embora não tenham sido enviadas pela totalidade dos estudantes, demonstrou que a maioria compreendeu a relação existente entre a disponibilidade de energia e a complexidade morfofisiológica crescente ao longo da evolução. Do mesmo modo, entenderam por que as outras hipóteses formuladas por eles próprios ou pelos colegas não poderiam explicar a distribuição dos tipos de ovos dos animais de diferentes filos. Nas aplicações presenciais passadas, por meio dos relatórios, não foi possível avaliar tão bem o desempenho individual e a compreensão por cada estudante da problemática exposta e discutida, visto que a atividade era realizada em equipe, a qual trazia uma conclusão supostamente coletiva.

\section{4 \\ LIÇÕES DO EaD, AS EXPERIÊNCIAS DO ERE E O FUTURO DO ENSINO}

Através da atividade aplicada remotamente e de forma emergencial por força da necessidade imposta pela pandemia da COVID-19, expôs-se os estudantes da turma pesquisada a uma situação de aprendizagem em que se tornaram protagonistas, sendo convidados a refletir e analisar uma situação sob um ponto de vista capaz de lhes retirar da "zona de conforto", bem 
como utilizar ferramentas digitais e metodologias inéditas e aparentemente motivadoras para a maioria dos estudantes.

Em particular na EaD, "o protagonismo do estudante é ponto crucial para seu sucesso, visto que este é o maior responsável pelo seu próprio processo de construção do conhecimento" (NONATO et al., 2029, p. 165). Nas duas últimas décadas, as transformações oriundas do desenvolvimento tecnológico desenham um cenário que convida os sujeitos contemporâneos a repensar suas práticas, inovar em seus campos profissionais e estar atentos às transformações (SANTANA, 2019). Em resposta a estas exigências, as instituições de Ensino Superior têm gradualmente implementado práticas diferenciadas e tecnologias no processo de ensinoaprendizagem (NONATO et al., 2019).

Vemos, com isso, um aumento crescente da oferta de cursos EaD, bem como da hibridização das graduações presenciais por intermédio de componentes curriculares a distância (NONATO et al., 2019; SILVA; PRADO; PASQUALINI, 2019). A EaD vem conquistando espaço principalmente em virtude de sua flexibilidade (SILVA; PRADO; PASQUALINI, 2019) e muitas de suas metodologias vêm sendo aplicadas nos cursos de graduação tanto por meio de disciplinas a distância quanto de nuances formativas diferenciadas e dinâmicas, que são urgentes para uma necessária reconfiguração do Ensino Superior (NONATO et al., 2019), trazendo o exercício efetivo de pedagogias que promovam a capacidade de resolver problemas e estimulem o pensamento crítico (YANG, 2015 apud NONATO et al., 2019). O EaD tem grande potencial para ofertar metodologias que "movimentem" o estudante, aplicando práticas investigativas e desafiadoras, que o incentivem a permanecer em contato com o ambiente virtual de aprendizagem (AVA) do curso (NONATO et al., 2019) e, consequentemente, estudando. Assim, os métodos da Educação a Distância se tornam

uma possibilidade ampliada para o Ensino Superior atender às exigências da sociedade contemporânea, no que tange à formação de profissionais com competências e habilidades para atuar no contexto profissional auxiliados pelas tecnologias nos processos comunicacionais e informacionais cotidianos (NONATO et al., 2019, p. 168).

A partir dessa tendência observada nos últimos anos, fruto de iniciativas individuais de um número crescente de professores experimentando o Ensino Híbrido (ROZA et al. 2019 apud SILVA; PRADO; PASQUALINI, 2019), verifica-se a gradual inclusão de diversos modos de ensinar e aprender, harmonizando estratégias tradicionais com 0 uso de tecnologias digitais, corroborando com a prática, a experimentação, a colaboração, o desenvolvimento da autonomia e da proatividade (SILVA; PRADO; PASQUALINI, 2019).

A partir de 2020 é possível que observemos um “divisor de águas” na utilização de práticas, estratégias e recursos educacionais em todos os níveis de ensino, mas, em particular no Ensino Superior, pois, abruptamente, um grande número de docentes deparou-se com a necessidade de aprender ou aprimorar seus conhecimentos relativos a ferramentas e metodologias para o Ensino Remoto, de modo que, muitos professores que não tinham familiaridade com tais recursos, perceberam que são capazes de utilizá-los e que eles trazem muitas vantagens no processo de ensino-aprendizagem. É possível, portanto, que esse seja um caminho sem volta rumo a uma grande mudança de paradigma na educação. 
Considera-se que a adequação da atividade investigativa sobre Tipos de Ovos - geralmente aplicada de modo presencial - para o Ensino Remoto Emergencial possibilitou aos estudantes de Ciências Biológicas da UFPR momentos de aprendizagem investigativa, nos quais foram protagonistas do processo de ensino-aprendizagem. Acredita-se que os principais fatores que contribuíram para tal resultado tenham sido a proposição de um problema capaz de instigar a curiosidade, munindo os estudantes com informações básicas na perspectiva da sala de aula invertida. O tempo expandido em comparação à modalidade presencial e a realização da atividade individual e não em grupo, permitiu espaço para reflexão e pesquisa em novas fontes de informação, favorecendo a elaboração de hipóteses coerentes e bem justificadas. Puderam, ainda, analisar diferentes hipóteses apresentadas e interpretá-las com base em evidências, lógica e informações científicas, chegando a conclusões que permitem a aplicação dos conhecimentos adquiridos em situações novas.

Assim, em breve, quando esses futuros biólogos confrontarem-se com outros problemas biológicos relacionados ao metabolismo energético e complexidade morfológica, certamente poderão acessar com mais facilidade o conhecimento adquirido por meio de raciocínio científico e não de mera memorização. 0 ponto negativo foi a baixa interação dos estudantes durante o encontro síncrono através de manifestação oral ou escrita, embora tenham participado pelo aplicativo Kahoot, fato observado em outras atividades do ERE com essa e outras turmas também.

Contudo, a qualidade dos textos apresentados tanto como hipóteses quanto conclusões, evidencia o bom nível de aproveitamento. A atividade proposta na forma remota, portanto, permitiu que os estudantes compreendessem, além do conteúdo, também o processo de construção do conhecimento científico, tendo sido considerada melhor que a aplicação presencial da forma como foi feita anteriormente pela mesma docente. Certamente, essa metodologia adaptada aos moldes da aplicação remota, será aplicada com outras turmas mesmo após o retorno das atividades presenciais em uma perspectiva de Ensino Híbrido.

\section{REFERÊNCIAS}

ASSUNÇÃO, M. P. B.; MIGLINO, M. A. Métodos alternativos no processo de ensino-aprendizagem em embriologia comparativa: desafios e perspectivas. Revista de Graduação USP, São Paulo, v. 4, n. 1, p. 147-154, 2020. Disponível em: https://doi.org/10.11606/issn.2525-376X.v4i1p147-154. Acesso em: 26 fev. 2021.

AZEVEDO M. C. P. S. Ensino por investigação: problematizando as atividades em sala de aula. In: CARVALHO, A. M. P. (org.). Ensino de ciências: unindo a pesquisa e a prática. São Paulo: Pioneira Thomson Learning, 2004.

AZEVÊDO, L. B.; FIREMAN, E. C. Sequência de ensino investigativa: problematizando aulas de ciências nos anos iniciais com conteúdos de eletricidade. Revista de Ensino de Ciências e Matemática - REnCiMa, São Paulo, v. 8, n. 2, p. 143-161, 2017. Disponível em: https://doi.org/10.26843/rencima.v8i2.1223. Acesso em: 26 fev. 2021. 
BACICH, L.; MORAN. J. (org.). Metodologias ativas para uma educação inovadora: uma abordagem téorico-prática. Porto Alegre: Penso, 2018.

BEHAR, P. A. 0 ensino remoto emergencial e a educação a distância. 2020. Disponível em: https://www.ufrgs.br/coronavirus/base/artigo-o-ensino-remoto-emergencial-e-a-educacao-a-distancia/. Acesso em: 18 nov. 2020.

BIZZO, N. Ciências: Fácil ou Difícil? São Paulo: Biruta, 2009.

BOTTENTUIT JUNIOR, J. B. O aplicativo Kahoot na educação: verificando os conhecimentos dos alunos em tempo real. Challenges 2017: Aprender nas Nuvens, Learning in the Clouds, p. 1587-1602, 2017. Disponível em: http://fatecead.com.br/ma/artigo01.pdf. Acesso em: 18 nov. 2020.

BRASIL. Ministério da Educação. Gabinete do Ministro. Nota Técnica Nº 32/2020/AssessoriaGAB/GM/GM. Análise do Parecer do Conselho Pleno do Conselho Nacional de Educação - CNE/CP n ${ }^{\circ}$ 5/2020 (SEI 2037135), que versa sobre a reorganização do calendário escolar e a possibilidade de cômputo de atividades não presenciais para fins de cumprimento da carga horária mínima anual, em razão da pandemia da COVID-19. 2020c. Disponível em: https://abmes.org.br/arquivos/documentos/nota-tecnicamec-32-02062020.pdf. Acesso em: 18 abr. 2020.

BRASIL. Ministério da Educação. Gabinete do Ministro. Portaria n. 343, de 17 de março de 2020. Dispõe sobre a substituição das aulas presenciais por aulas em meios digitais enquanto durar a situação de pandemia do Novo Coronavírus - COVID-19. Diário Oficial da União, Brasília, DF, n. 53, p. 39, 18 mar. 2020a. Disponível em:

http://www.planalto.gov.br/CCIVIL_03/Portaria/PRT/Portaria\%20n\%C2\%BA\%20343-20-mec.htm. Acesso em: 18 abr. 2020.

BRASIL. Ministério da Educação. Gabinete do Ministro. Portaria no. 544, de 16 de junho de 2020. Dispõe sobre a substituição das aulas presenciais por aulas em meios digitais, enquanto durar a situação de pandemia do novo coronavírus - Covid-19, e revoga as Portarias MEC n³ 343, de 17 de março de 2020, $n^{\circ}$ 345, de 19 de março de 2020, e n 473, de 12 de maio de 2020. Diário Oficial da União: seção 1, Brasília, DF, v. 114, p. 62, 17 jun. 2020b. Disponível em: https://www.in.gov.br/en/web/dou/-/portaria-n-544-de-16de-junho-de-2020-261924872. Acesso em: julho de 2020. Disponível em: . Acesso em: 26 jul. 2020.

DELLOS, R. Kahoot! A digital game resource for learning. In: International Journal of Instructional Technology and Distance Learning. v. 12, n. 4., p. 49-52, Apr. 2015. Disponível em: https://www.itdl.org/Journal/Apr_15/Apr15.pdf. Acesso em: 26 jul. 2020.

FARDO, M. L. A gamificação aplicada em ambientes de aprendizagem. Novas Tecnologias na Educação. Porto Alegre, v. 11, n. 1, p. 1-9, 2013. Disponível em: https://seer.ufrgs.br/renote/article/view/41629. Acesso em: 26 jul. 2020.

GERHARD, A. C.; ROCHA-FILHO, J. B. A fragmentação dos saberes na educação científica escolar na percepção de professores de uma escola de ensino médio. Investigações em Ensino de Ciências, Porto Alegre, v. 17, n. 1, p. 125-145, 2012. Disponível em: https://www.if.ufrgs.br/cref/ojs/index.php/ienci/article/view/210. Acesso em: 26 jul. 2020.

MAIA, M. D. S.; SILVA, D. G. Práticas pedagógicas em ambientes virtuais de aprendizagem: usos e abusos. EmRede: Revista de Educação a Distância, Porto Alegre, v. 7, n. 1, p. 81-95, 2020. Disponível em: https://www.aunirede.org.br/revista/index.php/emrede/article/view/555. Acesso em: 26 jul. 2020.

MERIGUETE, M. S. P. et al. Sala de aula invertida e rotação por estações: aplicação no projeto social Grupo Bizu De Prova. EmRede: Revista de Educação a Distância, Porto Alegre, v. 6, n. 2, p. 288-307, 2019. 
Disponível em: https://www.aunirede.org.br/revista/index.php/emrede/article/view/465. Acesso em: 18 nov. 2020

MORAES, H. L. B. et al. De ensino presencial para o remoto emergencial: adaptações, desafios e impactos na pós graduação. Interfaces Científicas, Aracaju, v. 10, n. 1, p. 180-193, 2020. Disponível em:

https://periodicos.set.edu.br/educacao/article/view/9271/4137. Acesso em: 18 nov. 2020.

NONATO, E. R. S. et al. Educação a distância, hibridismo e metodologias ativas: fundamentos conceituais para uma proposta de modelo pedagógico na oferta das disciplinas semipresenciais dos cursos

presenciais de graduação da UNEB. EmRede: Revista de Educação a Distância, Porto Alegre, v. 6, n. 2, p. 161-171, 2019. Disponível em:

https://www.aunirede.org.br/revista/index.php/emrede/article/view/489/440. Acesso em: 18 nov. 2020.

PARANÁ. Secretaria de Estado da Educação do Paraná. Diretrizes Curriculares da Educação Básica: Biologia. Curitiba: SEED, 2008. Disponível em:

http://www.educadores.diaadia.pr.gov.br/arquivos/File/diretrizes/dce_bio.pdf. Acesso em: 18 nov. 2020.

RABELLO, M. E. Lições do coronavírus: ensino remoto emergencial não é EAD. 2020. Disponível em: https://desafiosdaeducacao.grupoa.com.br/coronavirus-ensino-remoto/. Acesso em: 18 nov. 2020.

SÁ, E. F.; LIMA M. E. C. C.; AGUIAR JUNIOR, O. A construção de sentidos para o termo Ensino por Investigação no contexto de um curso de formação. Investigações em Ensino de Ciências, Porto Alegre, v. 16, n. 1, p. 79-102, 2011. Disponível em:

https://www.if.ufrgs.br/cref/ojs/index.php/ienci/article/view/247. Acesso em: 18 nov. 2020.

SANTANA, C. L. S. Pedagogias das conexões: ensinar e aprender na sociedade digital blended. EmRede: Revista de Educação a Distância, v. 6, n. 2, p. 185-202, 2019. Disponível em:

https://www.aunirede.org.br/revista/index.php/emrede/article/view/475. Acesso em: 18 nov. 2020.

SANTOS, E. Educação online para além da EaD: um fenômeno da cibercultura. In: Actas do X Congresso Internacional Galego-Português de Psicopedagogia. Braga: Universidade do Minho, 2009. Disponível em:

https://www.educacion.udc.es/grupos/gipdae/documentos/congreso/xcongreso/pdfs/t12/t12c427.pdf. Acesso em: 18 nov. 2020.

SANTOS, I. M.; GUIMARÃES, D.; CARVALHO, A. A. Flipped Classroom: Uma Experiência Com Alunos do $8^{\circ}$ Ano na Unidade de Sólidos Geométricos. In: MIRANDA, G. L.; MONTEIRO, M. E.; BRÁS, P. T. (org.). CONGRESSO INTERNACIONAL TIC E EDUCAÇÃO: TicEduca'2014, 3., 2014, Lisboa. Anais [...]. Lisboa: Instituto de Educação da Universidade de Lisboa, 2014. Disponível em: . Acesso em: 26 fev. 2021.

SILVA, A. P.; PRADO, R. C.; PASQUALINI, E. Ambientes híbridos de aprendizagem: entre a educação presencial e a educação a distância. EmRede: Revista de Educação a Distância, Porto Alegre, v. 6, n. 2, p. 276-287, 2019. Disponível em: https://www.aunirede.org.br/revista/index.php/emrede/article/view/477. Acesso em: 26 fev. 2021.

SILVA, E. M. D. A virtude do erro: uma visão construtiva da avaliação. Estudos em Avaliação Educacional, São Paulo, v. 19, n. 39, p. 91-112, jan./abr. 2008. Disponível em: http://www.fcc.org.br/pesquisa/publicacoes/eae/arquivos/1420/1420.pdf. Acesso em: 26 fev. 2021.

SILVA, S.; AFFELDT, D. R. Compreendendo as formas de interação no Moodle por uma educação a distância mais significante: uma abordagem enunciativa. EmRede: Revista de Educação a Distância, Porto Alegre, v. 7, n. 1, p. 55-68, 2020. Disponível em: https://www.aunirede.org.br/revista/index.php/emrede/article/view/541. Acesso em: 26 fev. 2021. 
TORI, R. Tecnologia e metodologia para uma educação sem distância. EmRede: Revista de Educação a Distância, Porto Alegre, v. 2, n. 2, p. 44-55, 2015. Disponível em:

https://www.aunirede.org.br/revista/index.php/emrede/article/view/64. Acesso em: 26 fev. 2021.

UNIVERSIDADE FEDERAL DO PARANÁ (UFPR). Resolução N 59/2020-CEPE. 23 jun. 2020. Regulamenta o período especial para o desenvolvimento de atividades de ensino nos cursos de educação superior, profissional e tecnológica da UFPR, no contexto das medidas de enfrentamento da pandemia de COVID19 no País. 2020a. Disponível em: http://www.soc.ufpr.br/portal/wp-

content/uploads/2020/06/Resolu\%C3\%A7\%C3\%A30-N\%C2\%BA-59-2020-CEPE.pdf. Acesso em: 15 dez. 2020.

UNIVERSIDADE FEDERAL DO PARANÁ (UFPR). Resolução Nº5/2020-CEPE. 09 out. 2020. Regulamenta, em caráter excepcional, novo período especial para o desenvolvimento de atividades de ensino nos cursos de educação superior, profissional e tecnológica da UFPR, no contexto das medidas de enfrentamento da pandemia de COVID-19 no País. 2020b. Disponível em:

http://www.soc.ufpr.br/portal/wp-content/uploads/2020/10/RESOLU\%C3\%87\%C3\%830-N\%C2\%BA-652020-CEPE.pdf. Acesso em: 15 dez. 2020.

ZANIN, A. C.; RIOS, F. S. O vitelo e a complexidade morfológica dos organismos: um jogo didático. In: CONGRESSO BRASILEIRO DE ZOOLOGIA, 3., 2014, Porto Alegre. Anais [...]. Porto Alegre: PUCRS, 2014. 